\title{
Early- and Late-Onset Depression in Late Life: A Prospective Study on Clinical and Structural Brain Characteristics and Response to Electroconvulsive Therapy
}

\author{
Annemiek Dols, M.D., Ph.D., Filip Bouckaert, M.D., Pascal Sienaert, M.D., Ph.D., \\ Didi Rbebergen, M.D., Ph.D., Kristof Vansteelandt, Ph.D., Mara ten Kate, M.D.,
} Francois-Laurent de Winter, M.D., Hannie C. Comijs, Ph.D., Louise Emsell, Ph.D., Mardien L. Oudega, M.D., Eric van Exel, M.D., Ph.D., Sigfried Schouws, Ph.D., Jasmien Obbels, M.Sc., Mike Wattjes, M.D., Ph.D., Frederik Barkbof, M.D., Ph.D., Piet Eikelenboom, M.D., Ph.D., Matbieu Vandenbulcke, M.D., Ph.D., Max L. Stek, M.D., Ph.D.

\begin{abstract}
Objective: The clinical profile of late-life depression (LLD) is frequently associated with cognitive impairment, aging-related brain changes, and somatic comorbidity. This twosite naturalistic longitudinal study aimed to explore differences in clinical and brain characteristics and response to electroconvulsive therapy (ECT) in early- (EOD) versus late-onset (LOD) late-life depression (respectively onset $<55$ and $\geq 55$ years). Methods: Between January 2011 and December 2013, 110 patients aged 55 years and older with ECT-treated unipolar depression were included in The Mood Disorders in Elderly treated with ECT study. Clinical profile and somatic health were assessed. Magnetic resonance imaging (MRI) scans were performed before the first ECT and visually rated. Results: Response rate was $78.2 \%$ and similar between the two sites but significantly higher in LOD compared with EOD (86.9 versus 67.3\%). Clinical, somatic, and brain characteristics were not different between EOD and LOD. Response to ECT was associated with late age at onset and presence of psychotic symptoms and not with structural MRI characteristics. In EOD only, the odds for a higher response were associated with a shorter index episode. Conclusion: The clinical profile, somatic
\end{abstract}

Received March 25, 2016; revised September 14, 2016; accepted September 15, 2016. From the Department of Old Age Psychiatry (AD, DR, HCC, MLO, EE, SS, PE, MLS), GGZ inGeest; EMGO+ Institute of Health and Care Research (AD, DR, HCC, MLO, EE, SS, MLS); Department of Radiology and Nuclear Medicine (MK, MW, FB), VU University Medical Center, Amsterdam, The Netherlands; Old-age Psychiatry (FB, F-LW, LE, MV); Academic Center for ECT and Neuromodulation (FB, PS, JO); Department of Psychiatry (KV); Research Group of Quantitative Psychology and Individual Differences (KV), University Psychiatric Center KU Leuven, Leuven/Kortenberg, Belgium; and Translational MRI (LE), Department of Imaging and Pathology, KU Leuven \& Radiology, University Hospitals Leuven, Leuven, Belgium. Send correspondence and reprint requests to Dr. Annemiek Dols, GGZ inGeest/VU University Medical Center, Department of Old Age Psychiatry, EMGO+ Institute of Health and Care Research, Amstelveenseweg 589, 1081JC, Amsterdam, Netherlands. e-mail: a.dols@ggzingeest.nl

Annemiek Dols and Filip Bouckaert contributed equally and share first authorship.

(C) 2016 American Association for Geriatric Psychiatry. Published by Elsevier Inc. All rights reserved.

http:/ /dx.doi.org/10.1016/j.jagp.2016.09.005 


\section{Early-and Late-Onset Depression in Late Life}

comorbidities, and brain characteristics in LLD were similar in EOD and LOD. Nevertheless, patients with LOD showed a superior response to ECT compared with patients with EOD. Our results indicate that ECT is very effective in LLD, even in vascular burdened patients. (Am J Geriatr Psychiatry 2016; $\mathbf{\square}: \mathbf{\square - \square} \mathbf{\text { ) }}$

Key Words: Depression, electroconvulsive therapy, response, late life, early onset, late onset, structural brain

\section{INTRODUCTION}

The etiology and clinical presentations of late-life depression (LLD) are rather heterogeneous compared with depression at a younger age. LLD is frequently associated with cognitive impairment, aging-related brain changes, and somatic comorbidity. ${ }^{1-3}$ Within LLD, subsets can be defined by age at onset, with a variable cut-off between studies ranging from 50 to 65 years. ${ }^{3}$ Earlyonset depression (EOD) is more often associated with a family history of affective disorders, ${ }^{4}$ anxiety features, and a more severe course of depression. ${ }^{3,5}$ In contrast, late-onset depression (LOD) is associated with somatic and neurodegenerative diseases ${ }^{6}$ contributing to its onset and leading to a course with worse neurocognitive performance,, 7, possibly as a prodrome of dementia. ${ }^{9}$ LOD is associated with a worse response to pharmacologic treatment as compared with $\mathrm{EOD},{ }^{3}$ possibly related to underlying cerebrovascular disease..$^{10-12}$ In a comprehensive review on structural brain imaging and pharmacotherapy in LLD, poor outcome was most robustly linked with white matter integrity. ${ }^{13}$ In addition, vascular risk factors were specifically linked to LOD, so clinical profiling by age at onset may be a tool to direct treatment strategy. Nevertheless, differences between EOD and LOD may depend on the samples studied, because depressive symptomatology of melancholic inpatients with respect to EOD and LOD were found to be more alike than different. ${ }^{14,15}$ Studies on treatment response in EOD and LOD combining vascular risk factors with imaging data on white matter integrity in well-defined samples are lacking to date.

In severe LLD, electroconvulsive therapy (ECT) is often the treatment of preference because it is more efficacious than pharmacotherapy, ${ }^{16,17}$ with response rates of $60 \%-70 \%{ }^{18,19}$ and with fewer side effects than pharmacotherapy. ${ }^{20}$ In line with the better response rates for EOD treated with pharmacotherapy, ${ }^{11,12}$ response to ECT may be better in EOD. Earlier studies by our group reported lower response rates to ECT in patients with medial temporal atrophy (MTA) but not white matter lesions ${ }^{21}$ and a faster response in patients with a smaller inferior frontal gyrus. ${ }^{22}$ However, these studies did not focus specifically on the possible role of age at disease onset.

The Mood Disorders in Elderly treated with ElectroConvulsive Therapy (MODECT), a two-site naturalistic, longitudinal study including older inpatients with severe unipolar depression treated with ECT, was designed to study clinical characteristics and outcome. The first aim of the present study was to describe the patients included in this cohort and to explore possible differences on demographic and clinical characteristics between the two inclusion sites. The second aim was to explore differences in clinical and structural brain characteristics between EOD versus LOD in a well-defined sample of LLD patients treated with ECT and to identify predictors of response to ECT with regard to age at onset. We hypothesized that LOD would be associated with somatic burden, age-related brain characteristics, and poorer response to ECT.

\section{METHODS}

\section{Sample}

Patients aged 55 years and older with severe unipolar depression according to the Diagnostic and Statistical Manual of Mental Disorders, Fourth Edition, Text Revision (DSM-IV-TR) criteria $^{23}$ referred for ECT were recruited from two tertiary psychiatric hospitals (GGZ inGeest, Amsterdam, the Netherlands and University Psychiatric Center, KU Leuven, Belgium). Exclusion criteria were a DSM-IV-TR diagnoses of bipolar disorder and schizoaffective disorder and a history of a major neurologic illness (including Parkinson disease, stroke, and dementia). The diagnoses were made by a psychiatrist and confirmed by the Mini International Neuropsychiatric Interview. ${ }^{24}$ Data collection began on 
FIGURE 1. Flow diagram of the study design and patient selection.

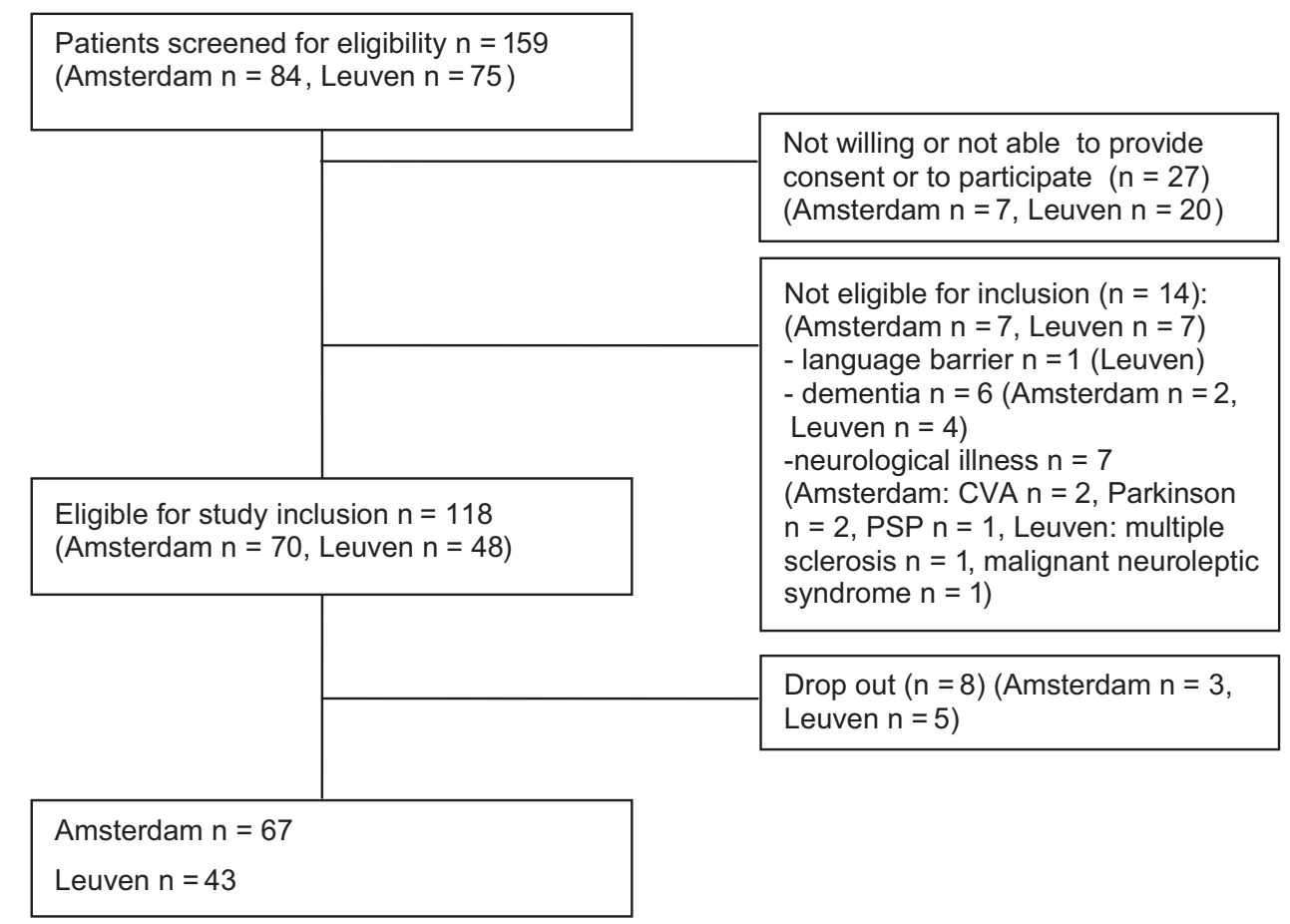

January 1, 2011 and finished on December 31, 2013; 110 patients were recruited: 67 in Amsterdam and 43 in Leuven (Figure 1).

\section{Assessments}

Demographic and clinical variables were obtained by interview and double-checked by chart review. Age at first depressive episode before 55 years was classified as EOD, whereas a first episode at 55 years and older was defined as LOD, as in our previous cohort. ${ }^{21}$ Previous treatments for the current depressive episode were assessed with the Antidepressant Treatment History Form..$^{25}$ Primary indication for ECT included pharmacotherapy resistance, life-threatening symptoms, elective, or other. The diagnosis of depression with or without psychotic symptoms was based on the DSM-IV-TR criteria.

Physical comorbidity and medication use were assessed in a semistructured interview inquiring about the presence of chronic obstructive pulmonary disease/asthma/emphysema, cardiovascular disease, myocardial infarction, hypertension, diabetes, cerebrovascular disease, arthrosis, (rheumatoid) arthritis, malignant neoplasms, migraine, thyroid disease, consequences of an accident, permanent disability due to surgery, Parkinson disease, other disease of the central nervous system, or other diseases. Smoking was categorized as never, ever, or current. Alcohol use was measured by two questions based on the Alcohol Use Disorders Identification Test ${ }^{26}$ on frequency and amount of alcohol consumption.

The Montgomery Åsberg Depression Scale (MADRS) was used to evaluate the depressive symptom severity during the treatment course ${ }^{27}$ In addition, we examined the patient's cognitive functioning by MiniMental State Exam (MMSE) ${ }^{28}$ before (T0), during (after 3 weeks: T1), and 1 week after the ECT course (T2). The MADRS and the MMSE were collected by welltrained research nurses who were blinded to clinical information, including information on age at onset.

\section{Magnetic Resonance Imaging}

Whole-brain scans were obtained at baseline using a whole-brain 3T magnetic resonance imaging (MRI) system (General Electric Signa HDxt, Milwaukee, 
WI, USA, in Amsterdam, Philips Intera, Best, The Netherlands, in Leuven). We acquired structural threedimensional T1-weighted images and axial fluidattenuated inversion recovery (FLAIR).

At baseline, white matter hyperintensities (WMHs) were rated on axial FLAIR images using the Fazekas scale $^{29}$ and the Age-Related White Matter Changes scale. ${ }^{30}$ The Fazekas scale is a whole-brain scale ranging from 0 (no WMH) to 3 (large confluent areas of WMHs). The Age-Related White Matter Changes scale assesses WMH in 10 different brain regions (including the basal ganglia), the score per region ranging from 0 to 3. MTA was rated on the oblique coronal threedimensional T1 images using the Scheltens scale ${ }^{31}$ ranging from 0 to 4 . We calculated the mean of leftand right-hemispheric score. Scores of both sides were summed up and divided by 2. Cortical atrophy was assessed on axial FLAIR images using the Pasquier four-point global cortical atrophy rating scale. ${ }^{32}$ Scores of left and right hemisphere were summed up and divided by 2 . Periventricular WMHs were rated separately on a three-point scale ranging from 0 (no periventricular $\mathrm{WMH})$ to $2(>5 \mathrm{~mm})$. An experienced neuroradiologist, who was blinded to all clinical information, reviewed all images.

\section{Administration of ECT}

Patients received twice-weekly ECT in accordance with Dutch standards. ${ }^{33}$ A course started with right unilateral ECT. All treatments were administered with the Thymatron System IV (Somatics, LLC, Lake Bluff, IL, USA) (maximum energy 200\%, 1,008 C). The stimulus intensity was determined by empirical dose titration at the first treatment, for right unilateral ECT six times the initial seizure threshold and for bilateral ECT 1.5 times seizure threshold. All patients were treated with brief-pulse ECT (0.5-1.0 ms). A motor seizure of less than 20 seconds was considered inadequate and the dose was subsequently raised according to Dutch guidelines. $^{34}$

Clinical evaluation was carried out weekly. Switching to bilateral ECT was applied when the clinical condition worsened (i.e., an increase in total MADRS scores, presence of debilitating psychotic features, increased suicidality, dehydration or weight loss, or when after six unilateral treatments there was no clinical improvement according to the judgment of the treating psychiatrist). ECT was continued until the patients achieved a MADRS score of less than 10 at two consecutive ratings with a week interval or stopped when patients showed no further improvement in clinical condition during the last 2 weeks of ECT sessions after a minimum of six unilateral and six bilateral sessions. Psychotropic medication was discontinued at least 1 week before ECT or, if deemed impossible, kept stable from 6 weeks before ECT and during the ECT course.

\section{Response and Remission}

Remission was defined as a MADRS score lower than 10 points after ECT at two consecutive weekly assessments. Response was defined as a decrease in MADRS scores of at least $50 \%{ }^{35}$

\section{Ethical Issues}

The study protocol of MODECT was approved centrally by the Ethical Review Board of the VU University Medical Center and subsequently by the Ethical Review Board of the Leuven University Hospitals and conducted according to the Declaration of Helsinki (clinicaltrials.gov; NCT02667353). Written informed consent was obtained from all patients at the start of the baseline assessment.

\section{Statistics}

Data were analyzed using SPSS, version 21 (SPSS Inc., Chicago, IL). For demographic data, group differences in continuous variables were determined by independent $t$ tests. If a variable was not normally distributed after log-transformation, a Mann-Whitney test was used and a $\mathrm{z}$ approximation was reported. Group differences in categorical variables were calculated using $\chi^{2}$ tests.

To examine differences in change over time on MMSE between subjects from Amsterdam versus Leuven and with EOD versus LOD, we estimated a linear mixed model with measurements occasions (T0, $\mathrm{T} 1$, and T2) nested within subjects. A linear mixed model was used with MMSE as dependent variable, random intercept, and fixed effects for time (T0, T1, T2), group (Amsterdam versus Leuven, EOD versus LOD), and time $\times$ group interaction. Post-hoc tests were performed using the Tukey-Kramer adjustment. 
Bivariate and multivariate logistic regression analyses were performed in the complete group and in both onset groups separately to investigate the relationship between clinical variables and response to ECT. We selected variables showing $\mathrm{p}<0.05$ as input for a multiple logistic regression model to evaluate their unique predictive value. To prevent multicollinearity, we computed the correlation coefficients between all independent variables. When the correlation coefficient was higher than 0.80 , we did not include these variables in the same model. To study whether the association between clinical variables and response was the same for EOD and LOD, interaction (onset $\times$ clinical variable) terms were tested. A $p<0.05$ was considered statistically significant.

\section{RESULTS}

\section{Demographics and Clinical Characteristics}

The baseline sample consisted of 110 severely depressed patients with a mean age of 73.0 years (standard deviation: 8.45) and 72 women (66.1\%) (Table 1). Patients received a median of two antidepressant treatments, thus establishing failure to respond to pharmacotherapy. The Leuven site included more patients with pharmacotherapy resistance as the primary indication, with a higher number of antidepressant medication trials (Table 1). However, the medication resistance score was not significantly different between the two sites (Table 1). In the Amsterdam sample there was more somatic comorbidity, specifically cardiovascular disease, and more prominent periventricular WMHs in the brain (Table 1).

Response rate was $78.2 \%$. The response and remission rates were not statistically different between the two sites (response: Leuven 86.0 versus Amsterdam 73.1\%; remission: Leuven 76.7 versus Amsterdam $59.7 \%$ ) (Table 1). At the Amsterdam site the rate of switching to bilateral ECT was higher $\left(\chi^{2}=4.61, \mathrm{df}=1\right.$, $\mathrm{p}=0.03$ ).

MMSE scores increased significantly over time $(\mathrm{F}(2,166)=9.96, \mathrm{p}<0.0001)$, with MMSE scores at baseline significantly lower than 1 week after the ECT course $(t(166)=-4.46, p<0.0001)$. There were no significant differences between MMSE scores at baseline and during the course of ECT (mean: 24.2 and 25.2, respectively) $(\mathrm{t}(166)=-2.19, \mathrm{p}=0.08)$ and between MMSE scores during and 1 week after the ECT course (mean: 25.2 and 26.3, respectively) $(\mathrm{t}(166)=-2.02$, $\mathrm{p}=0.11$ ).

\section{EOD versus LOD}

Patients with LOD had a higher response rate $(86.9 \%$ versus $67.3 \%, \chi^{2} 6.08, \mathrm{df}=1, \mathrm{p}=0.01$, Table 2 ), with a similar number of ECT sessions. The clinical profile of LOD versus EOD was similar in terms of depressive and psychotic symptoms and medication resistance. Somatic comorbidity was not different between EOD and LOD, and neither were the structural brain characteristics. Patients with EOD were younger and experienced more depressive episodes and more admissions (Table 2). Cognition measured with MMSE at any time point was higher in patients with EOD compared with $\operatorname{LOD}(\mathrm{F}(1,166)=4.22, \mathrm{p}=0.04)$. However, differences in change over time did not occur in MMSE scores between EOD and $\operatorname{LOD}(\mathrm{F}(2,166)=1.53, \mathrm{p}=0.22)$.

\section{Factors Associated with Response}

Higher response rates in the total sample were bivariately associated with later age at onset, lower medication resistance score, and more psychotic symptoms (Table 3). In multiple logistic regression analyses, a high response rate remained associated with later age at onset (odds ratio [OR]: 3.06; 95\% confidence interval [CI]: 1.07-8.70; Wald $\left.\chi^{2} 4.39, \mathrm{df}=1, \mathrm{p}=0.04\right)$ and more psychotic symptoms (OR: 3.30; 95\% CI: 1.12-9.74; Wald $\left.\chi^{2} 4.67, \mathrm{df}=1, \mathrm{p}=0.03\right)$ but not with medication resistance score (OR: 0.69; 95\% CI: 0.45-1.03; Wald $\chi^{2} 3.24$, $\mathrm{df}=1, \mathrm{p}=0.07$ ) (data not shown). The multivariate model explained $21.8 \%$ of the variance in response versus nonresponse $\left(\chi^{2} 15.39, \mathrm{df}=3, \mathrm{p}=0.002\right)$.

To study whether the associations between predictors of response to ECT were different for LOD compared with EOD, we examined the interaction terms EOD/LOD $\times$ predictor variable in the logistic regression models (Table 3 ) and performed stratified analyses according to age at onset status. The interaction terms "EOD/LOD $\times$ duration of index episode" and "EOD/LOD $\times$ MTA" were statistically significant. Stratified analyses showed that in EOD, a shorter duration of index episode was associated with higher response rates (OR: 0.92; 95\% CI: 0.86-0.98; Wald $\chi^{2}$ 6.73, $\mathrm{df}=1, \mathrm{p}=0.01$, Table 3), whereas in LOD no significant 
Early- and Late-Onset Depression in Late Life

TABLE 1. Baseline Demographic and Clinical Characteristics, ECT Characteristics, and Clinical Status after ECT

\begin{tabular}{|c|c|c|c|c|}
\hline & $\begin{array}{c}\text { Total } \\
(\mathrm{N}=110)\end{array}$ & $\begin{array}{l}\text { Amsterdam } \\
(N=67)\end{array}$ & $\begin{array}{c}\text { Leuven } \\
(\mathrm{N}=43)\end{array}$ & $\begin{array}{l}\text { Statistics } \\
\chi^{2} / \mathbf{t}(\mathbf{d f}) \mathbf{p} \text { value }\end{array}$ \\
\hline Mean age, yr (SD) & $73.0(8.45)$ & $72.8(9.23)$ & $73.2(7.38)$ & $-0.26(102) 0.79$ \\
\hline $55-59$ & $10(9.1)$ & $8(11.9)$ & $2(4.7)$ & \\
\hline $60-69$ & $32(29.1)$ & $19(28.4)$ & $13(30.2)$ & \\
\hline $70-79$ & $38(34.5)$ & $21(31.3)$ & $17(39.5)$ & \\
\hline 80 and over & $30(27.3)$ & $19(28.4)$ & $11(25.6)$ & \\
\hline Gender, female & $73(66.4)$ & $43(64.2)$ & $30(69.8)$ & 0.37 (1) 0.55 \\
\hline Marital status & & & & 11.0 (3) 0.01 \\
\hline Never married & $16(14.5)$ & $14(20.9)$ & $2(4.6)$ & \\
\hline Married & $57(52.3)$ & $28(41.8)$ & $29(69.0)$ & \\
\hline Divorced & $9(8.3)$ & $8(11.9)$ & $1(2.3)$ & \\
\hline Widowed & $28(25.7)$ & $17(25.4)$ & $11(26.2)$ & \\
\hline Level of education & $93(84.5)$ & $51(76.1)$ & $42(2.3)$ & $9.12(7) 0.25$ \\
\hline Low & $14(12.7)$ & $6(8.96)$ & $8(18.6)$ & \\
\hline Middle & $51(46.4)$ & $25(37.3)$ & $26(60.5)$ & \\
\hline High & $28(25.5)$ & $20(29.9)$ & $8(18.6)$ & \\
\hline Median duration of admission before ECT, mo (IQR) & $1(4)$ & $1(4)$ & $1(2)$ & MW 0.38 \\
\hline Previous depressive episodes, present & $88(80.0)$ & $56(83.6)$ & $32(73.8)$ & MW 0.54 \\
\hline Median (IQR) & $3(2)$ & $3(2)$ & $3(3)$ & \\
\hline Number of admissions, median (IQR) & $3(3)$ & $3(3)$ & $3(3)$ & MW 0.13 \\
\hline Duration of all admissions, median (IQR) & $9(11)$ & $10(13)$ & $6.5(10)$ & MW 0.05 \\
\hline Duration of current episode, mo & $103(84.5)$ & $65(97.0)$ & $38(88.4)$ & MW 0.41 \\
\hline Median (IQR) & $6(9)$ & $7(15)$ & $6(4)$ & \\
\hline Age at onset of first depression & & & & $0.72(1) 0.40$ \\
\hline Early & $49(44.5)$ & $32(47.8)$ & $17(39.5)$ & \\
\hline Late (>55 yr) & $61(55.5)$ & $35(52.2)$ & $26(60.5)$ & \\
\hline ATHF score & $99(90.0)$ & $60(89.6)$ & $39(90.7)$ & \\
\hline Number of depressant trials, median (IQR) & $2.0(2)$ & $1.0(1.0)$ & $2.0(2.0)$ & MW 0.035 \\
\hline Resistance score of depressant trials, mean (SD) & $3.1(1.35)$ & $2.8(1.42)$ & $3.5(1.14)$ & $8.39(5) 0.14$ \\
\hline Indication for ECT & & & & $6.05(3) 0.11$ \\
\hline Pharmacotherapy resistance & $64(58.2)$ & $34(50.7)$ & $30(69.8)$ & \\
\hline Life threatening symptoms & $33(30.0)$ & $24(35.8)$ & $9(20.9)$ & \\
\hline Elective & $10(9.1)$ & $8(11.9)$ & $2(4.7)$ & \\
\hline Other & $3(2.7)$ & $1(1.5)$ & $2(4.7)$ & \\
\hline DSM-IV-TR diagnosis & & & & $0.12(1) 0.73$ \\
\hline MDD & $54(49.1)$ & $32(47.8)$ & $22(51.2)$ & \\
\hline MDD with psychosis & $56(50.9)$ & $35(52.2)$ & $21(48.8)$ & \\
\hline \multicolumn{5}{|l|}{ Physical comorbidity } \\
\hline None & $27(24.5)$ & $10(14.9)$ & $17(39.5)$ & $8.56(1) 0.003$ \\
\hline $\begin{array}{l}\text { Chronic obstructive pulmonary disease, asthma, emphysema, } \\
\text { chronic bronchitis (\%) }\end{array}$ & $12(10.9)$ & $7(10.4)$ & $5(11.6)$ & 0.04 (1) 0.85 \\
\hline Cardiovascular disease, myocardial infarction & $29(26.4)$ & $24(35.8)$ & $5(11.6)$ & 7.90 (1) 0.005 \\
\hline Hypertension & $33(30.0)$ & $23(34.3)$ & $10(23.3)$ & 1.53 (1) 0.22 \\
\hline Diabetes & $10(9.1)$ & $4(6.0)$ & $6(14.0)$ & $2.02(1) 0.16$ \\
\hline Cerebrovascular disease & $4(3.6)$ & $4(6.0)$ & $0(0.0)$ & 2.66 (1) 0.10 \\
\hline Arthrosis, (rheumatoid) arthritis & $13(11.8)$ & $11(16.4)$ & $2(4.7)$ & 3.48 (1) 0.06 \\
\hline Malignant neoplasms & $19(17.3)$ & $15(22.4)$ & $4(9.3)$ & $3.14(1) 0.08$ \\
\hline Thyroid disease & $13(11.8)$ & $10(14.9)$ & $3(7.0)$ & 1.59 (1) 0.21 \\
\hline Smoking & $94(85.4)$ & $65(97.0)$ & $29(67.4)$ & 0.64 (2) 0.73 \\
\hline Never & $60(54.5)$ & $41(61.2)$ & $19(44.2)$ & \\
\hline Ever, but not current & $10(9.1)$ & $8(11.9)$ & $2(4.7)$ & \\
\hline Current & $24(21.8)$ & $16(23.9)$ & $8(18.6)$ & \\
\hline Alcohol & $102(92.7)$ & $60(89.5)$ & $42(97.7)$ & MW 0.23 \\
\hline Never & $67(60.9)$ & $42(62.7)$ & $25(58.1)$ & \\
\hline Units per week, median (IQR) & $1.0(0)$ & $1.0(0)$ & $1(1.5)$ & \\
\hline MADRS & $109(99.1)$ & $66(98.5)$ & $43(100)$ & $4.42(107) 0.14$ \\
\hline Mean (SD) & $33.6(8.63)$ & $32.6(9.38)$ & $35.1(7.15)$ & \\
\hline MMSE score before ECT & $93(84.5)$ & $51(76.1)$ & $42(97.7)$ & $0.59(166) 0.99^{*}$ \\
\hline Mean (standard error) & $24.2(0.45)$ & $24.5(0.59)$ & $24.0(0.67)$ & \\
\hline MMSE score during ECT course & $83(75.5)$ & $43(64.2)$ & $40(93.0)$ & $-0.27(166)$ \\
\hline Mean (standard error) & $25.2(0.47)$ & $25.1(0.63)$ & $25.4(0.69)$ & $0.99^{*}$ \\
\hline
\end{tabular}


Table 1 (continued)

\begin{tabular}{|c|c|c|c|c|}
\hline & $\begin{array}{c}\text { Total } \\
(\mathbf{N}=\mathbf{1 1 0})\end{array}$ & $\begin{array}{c}\text { Amsterdam } \\
(N=67)\end{array}$ & $\begin{array}{c}\text { Leuven } \\
(\mathrm{N}=43)\end{array}$ & $\begin{array}{c}\text { Statistics } \\
\chi^{2} / \mathbf{t} \text { (df) p value }\end{array}$ \\
\hline MMSE score after last ECT & $103(93.6)$ & $60(89.6)$ & $43(100)$ & $-1.17(166)$ \\
\hline Mean (standard error) & $26.3(0.44)$ & $25.8(0.56)$ & $26.8(0.67)$ & $0.85^{*}$ \\
\hline MRI at baseline & $80(72.7)$ & $42(62.7)$ & $38(88.4)$ & \\
\hline Medial temporal lobe atrophy score (median, IQR) & $1(1.5)$ & $1(1.5)$ & $1(1)$ & MW 0.37 \\
\hline Global cortical atrophy score (median, IQR) & $1(1)$ & $1(1)$ & $1(1)$ & MW 0.48 \\
\hline Fazekas (median, IQR) & $1(1)$ & $1(1)$ & $1(0.3)$ & MW 0.08 \\
\hline Periventricular WMHs (median, IQR) & $1(1)$ & $1(1)$ & $1(0)$ & MW 0.02 \\
\hline ARWMC total score (median, IQR) & $6.5(7)$ & $8(7.3)$ & $6(6.3)$ & MW 0.08 \\
\hline \multicolumn{5}{|l|}{ ECT characteristics } \\
\hline Number of ECT treatments, mean (SD) & $11.7(5.4)$ & $11.8(6.3)$ & $11.5(3.7)$ & $0.21(107) 0.85$ \\
\hline Patients treated unilateral & $104(94.5)$ & $61(91)$ & $43(100)$ & \\
\hline Patients treated bilateral & $6(5.5)$ & $6(9)$ & $0(0)$ & 4.61 (1) 0.03 \\
\hline Patients switched to bilateral & $34(30.9)$ & $25(37.3)$ & $9(20.9)$ & \\
\hline \multicolumn{5}{|l|}{ Clinical status 1 week after ECT } \\
\hline Response to $\mathrm{ECT}^{\dagger}$ & $86(78.2)$ & $49(73.1)$ & $37(86.0)$ & 2.56 (1) 0.11 \\
\hline Remission after $\mathrm{ECT}^{\ddagger}$ & $73(66.4)$ & $40(59.7)$ & $33(76.7)$ & $3.41(1) 0.07$ \\
\hline \multicolumn{5}{|c|}{$\begin{array}{l}\text { Notes: Values are total number of cases with percents in parentheses, unless otherwise noted. Statistical tests are based on } \chi^{2} \text { statistics for } \\
\text { categorical variables, } \mathrm{t} \text { tests for continuous variables, Mann-Whitney (MW) test for variables with non-normal distribution, at a significance } \\
\text { level of } 5 \% \text {. MW was reported as a z approximation. Education: low (no education, primary school), middle (high school, vocational train- } \\
\text { ing), high (college, university). SD: standard deviation; IQR: interquartile range; ATHF: Antidepressant Treatment History Form, MDD: major } \\
\text { depressive disorder; ARWMC: Age-Related White Matter Changes scale. } \\
\text { *Tukey-Kramer adjusted post hoc tests for Amsterdam/Leuven } \times \text { time interaction in linear mixed model, test for interaction: F(2,166) =1.46, } \\
\mathrm{p}=0.24 \text {. } \\
\quad{ }^{+} \text {Response to ECT is defined as } 50 \% \text { improvement or more in MADRS scores from baseline during a course of ECT. } \\
{ }^{+} \text {Remission after ECT is defined as a MADRS score lower than } 10 \text { points. }\end{array}$} \\
\hline
\end{tabular}

association was found. Furthermore, in EOD the odds for response were higher when having more hippocampal atrophy (OR: 3.20; 95\% CI: 0.73-14.1; Wald $\chi^{2}$ $2.37, \mathrm{df}=1, \mathrm{p}=0.12$, Table 3 ), whereas the odds for response in LOD were higher when having less hippocampal atrophy (OR: 0.49; 95\% CI: 0.17-1.44; Wald $\chi^{2} 1.70, \mathrm{df}=1, \mathrm{p}=0.19$, Table 3 ). However, both associations were not statistically significant.

\section{DISCUSSION}

The MODECT is a two-site prospective intervention study examining clinical outcome in EOD and LOD after ECT in 110 patients with severe LLD. Response rate was $78.2 \%$ and was similar between the two sites. The clinical profile, somatic comorbidities, and structural brain characteristics were not different between EOD and LOD. Nevertheless, patients with LOD showed a superior response to ECT compared with patients with EOD. Response to ECT was associated with late age at onset and presence of psychotic symptoms but not with structural brain characteristics. Our results indicate that ECT is very effective in LLD, even with vascular burden.

\section{Sample}

Patients had received a median of two antidepressant trials, confirming that ECT is very effective even in patients who failed to respond to pharmacotherapy. Patients from the two sites were very comparable; however, the Leuven site included more patients with pharmacotherapy resistance and the Amsterdam sample had more somatic comorbidity and more WMHs. This is in line with the facts that the Leuven site is known for their referrals of pharmacotherapy-resistant patients and the Amsterdam site is a tertiary referral center for ECT in frail severely depressed older patients. The preponderance of somatic comorbidity in the Amsterdam sample might have led to a higher rate of switching from right unilateral to bilateral ECT. Indeed, physically frail patients very often show life-threatening symptoms because of refusal of food and fluids, justifying the application of bilateral electrode position, given its more rapid symptom reduction. ${ }^{36}$

The response rate was $78.2 \%$, similar between the two sites, and at the higher end of the range previously reported in LLD. ${ }^{37}$ Response to ECT was associated with late age at onset and presence of 


\section{Early- and Late-Onset Depression in Late Life}

TABLE 2. Age at Onset and Clinical and Structural Brain Characteristics

\begin{tabular}{|c|c|c|c|}
\hline & $\begin{array}{c}\text { EOD } \\
(N=49)\end{array}$ & $\begin{array}{c}\text { LOD } \\
(\mathbf{N}=\mathbf{6 1}) \\
\end{array}$ & $\begin{array}{c}\text { Statistics } \\
\chi^{2} / \mathbf{t} \text { (df) } \mathbf{p} \text { value } \\
\end{array}$ \\
\hline Mean age, yr (SD) & $69.3(7.6)$ & $75.8(8.1)$ & $-4.34(108)<0.001$ \\
\hline Gender, female & $31(63.3)$ & $42(68.9)$ & $0.38(1) 0.54$ \\
\hline Previous depressive episodes, present & $49(100)$ & $40(65.6)$ & MW 0.003 \\
\hline Median (IQR) & $4(3)$ & $2(2)$ & MW 0.003 \\
\hline Number of admissions, median (IQR) & $4(4)$ & $2(2)$ & MW $<0.001$ \\
\hline Duration of current episode, mo, median (IQR) & $6(12)$ & $6(10)$ & MW 0.13 \\
\hline \multicolumn{4}{|l|}{ ATHF score } \\
\hline Number of depressant trials, median (IQR) & $2.0(2.0)$ & $2.0(2.0)$ & MW 0.59 \\
\hline Resistance score of depressant trials, mean $( \pm \mathrm{SD})$ & $3.29(1.26)$ & $2.87(1.40)$ & $1.55(96.3) 0.12$ \\
\hline DSM-IV-TR diagnosis MDD with psychosis & $21(42.9)$ & $35(57.4)$ & $2.29(1) 0.13$ \\
\hline \multicolumn{4}{|l|}{ Physical comorbidity } \\
\hline None & $12(24.5)$ & 15 (24.6) & $0.0(1) 0.99$ \\
\hline Chronic obstructive pulmonary disease, asthma, emphysema, chronic bronchitis & $6(12.2)$ & $6(9.8)$ & $0.16(1) 0.69$ \\
\hline Cardiovascular disease, myocardial infarction & $11(22.4)$ & $18(29.5)$ & $0.70(10) 0.41$ \\
\hline Hypertension & $14(28.6)$ & $19(31.1)$ & 0.09 (1) 0.77 \\
\hline Diabetes & $3(6.1)$ & $7(11.5)$ & $0.94(1) 0.33$ \\
\hline Cerebrovascular disease & $0(0)$ & $4(6.6)$ & Fisher 0.13 \\
\hline Arthrosis, (rheumatoid) arthritis & $7(14.3)$ & $6(9.8)$ & $0.52(1) 0.47$ \\
\hline Malignant neoplasms & $9(18.4)$ & $10(16.4)$ & 0.07 (1) 0.79 \\
\hline Thyroid disease & $5(10.2)$ & $8(13.1)$ & 0.22 (1) 0.64 \\
\hline MADRS & $49(100)$ & $60(98.4)$ & $-0.62(107) 0.54$ \\
\hline Mean (SD) & $33.0(8.77)$ & $34.0(8.59)$ & \\
\hline MMSE score before ECT & $42(85.7)$ & $51(83.4)$ & \\
\hline Mean (standard error) & $24.5(0.66)$ & $24.04(0.59)$ & $0.56(166) 0.99^{*}$ \\
\hline MMSE score during ECT course & $35(71.4)$ & $48(78.7)$ & \\
\hline Mean (standard error) & $26.34(0.70)$ & $24.37(0.61)$ & $2.13(166) 0.28^{*}$ \\
\hline MMSE score after last ECT & $44(89.8)$ & $59(96.7)$ & \\
\hline Mean (standard error) & $27.25(0.65)$ & $25.39(0.56)$ & $2.77(166) 0.26^{*}$ \\
\hline MRI at baseline & 37 & 43 & \\
\hline Medial temporal lobe atrophy score (median, IQR) & $1(1)$ & $1(1.5)$ & MW 0.10 \\
\hline Global cortical atrophy score (median, IQR) & $1(1)$ & $1(0)$ & MW 0.08 \\
\hline Fazekas (median, IQR) & $1(1)$ & $1(1)$ & MW 0.20 \\
\hline WMHs (median, IQR) & $1(1)$ & $1(1)$ & MW 0.34 \\
\hline ARWMC total score (median, IQR) & $6(6.5)$ & $8(7)$ & MW 0.43 \\
\hline Number of ECT sessions, mean (SD) & $12.8(6.2)$ & $11.0(4.9)$ & $1.58(90.2) 0.12$ \\
\hline Response & $33(67.3)$ & $53(86.9)$ & $6.08(1) 0.01$ \\
\hline
\end{tabular}

Notes: Values are total number of cases with percents in parentheses, unless otherwise noted. Statistical tests are based on $\chi^{2}$ statistics for categorical variables, $\mathrm{t}$ tests for continuous variables, Mann-Whitney (MW) test for variables without normal distribution, at a significance level of 5\%. MW was reported as a z approximation. SD standard deviation, IQR interquartile range. SD: standard deviation; IQR: interquartile range; ATHF: Antidepressant Treatment History Form, MDD: major depressive disorder; ARWMC: Age-Related White Matter Changes scale.

*Tukey-Kramer adjusted post hoc tests for early/late onset $\times$ time interaction in linear mixed model, test for interaction: $\mathrm{F}(2,166)=1.53$, $\mathrm{p}=0.22$.

psychotic symptoms but not with structural MRI characteristics.

\section{EOD versus LOD}

In our sample of patients with severe LLD, the clinical profile of EOD and LOD was very similar, as was shown in previous studies in clinical samples with severe depression. ${ }^{15,38,39}$ Symptom profile or severity and duration of current episode were not different in EOD or LOD in our sample of severe LLD patients eligible for ECT. Contrary to our hypothesis, somatic comorbidity and structural brain characteristics were similar in EOD and LOD in our sample. Patients with LOD had a higher response rate compared with patients with EOD.

Although the MMSE was lower in LOD than in EOD throughout the study, there was no difference in cognitive improvement, indicating that age at onset does not affect cognitive outcome. Examining factors related to response in EOD and LOD, we found that in EOD response was associated with shorter duration of index episode (OR: $0.92 ; 95 \%$ CI: $0.86-0.98)$, but we failed to identify significant associations with response in LOD. 
TABLE 3. Factors Associated with ECT Response

\begin{tabular}{|c|c|c|c|c|c|c|c|c|c|c|}
\hline & & & & \multicolumn{7}{|c|}{ Bivariate Logistic Regression Analyses and Interaction Term "Age at Onset" } \\
\hline & \multicolumn{3}{|c|}{ Bivariate Logistic Regression Analyses } & \multicolumn{3}{|c|}{ EOD } & \multicolumn{3}{|c|}{ LOD } & \multirow[b]{2}{*}{ p Interaction } \\
\hline & OR $(95 \% \mathrm{CI})$ & Wald $\chi^{2}$ & $\mathbf{p}$ & OR $(95 \% \mathrm{CI})$ & Wald $\chi^{2}$ & $\mathbf{p}$ & OR $(95 \% \mathrm{CI})$ & Wald $\chi^{2}$ & $\mathbf{p}$ & \\
\hline$\{$ Age, yr & $1.03(0.97-1.08)$ & 0.89 & 0.35 & $0.97(0.90-1.05)$ & 0.51 & 0.48 & $1.07(0.98-1.17)$ & 2.54 & 0.11 & 0.10 \\
\hline Duration of index episode, mo & $0.98(0.96-1.01)$ & 2.50 & 0.11 & $0.92(0.86-0.98)$ & 6.73 & 0.01 & $1.02(0.95-1.09)$ & 0.25 & 0.62 & 0.03 \\
\hline Age at onset & $2.80(1.11-7.07)$ & 5.75 & 0.03 & & & & & & & \\
\hline \multicolumn{11}{|l|}{ Medication resistance: } \\
\hline number of antidepressant trials & $0.75(0.50-1.13)$ & 1.87 & 0.17 & $0.98(0.56-1.70)$ & 0.01 & 0.93 & $0.52(0.27-1.02)$ & 3.57 & 0.06 & 0.16 \\
\hline Medication resistance score & $0.63(0.42-0.95)$ & 4.84 & 0.03 & $0.60(0.34-1.06)$ & 3.11 & 0.08 & $0.85(0.47-1.53)$ & 0.31 & 0.58 & 0.42 \\
\hline Depression symptoms & $1.02(0.97-1.08)$ & 0.70 & 0.40 & $1.01(0.97-1.06)$ & 0.19 & 0.66 & $1.00(0.94-1.05)$ & 0.02 & 0.88 & 0.69 \\
\hline Psychotic symptoms & $3.22(1.21-8.55)$ & 5.48 & 0.02 & $3.19(0.85-12.0)$ & 2.96 & 0.09 & $1.85(0.44-7.69)$ & 0.71 & 0.40 & 0.58 \\
\hline No somatic illness & $0.37(0.10-1.36)$ & 2.27 & 0.13 & $0.33(0.06-1.72)$ & 1.73 & 0.19 & $0.34(0.04-2.96)$ & 0.96 & 0.33 & 0.98 \\
\hline Cardiovascular diseases & $0.65(0.24-1.72)$ & 0.76 & 0.38 & $0.30(0.07-1.19)$ & 2.92 & 0.09 & $0.81(0.18-3.67)$ & 0.07 & 0.79 & 0.34 \\
\hline MTA & $1.08(0.50-2.33)$ & 0.04 & 0.85 & $3.20(0.73-14.1)$ & 2.37 & 0.12 & $0.49(0.17-1.44)$ & 1.70 & 0.19 & 0.04 \\
\hline GCA & $0.71(0.32-1.60)$ & 0.67 & 0.41 & $0.42(0.12-1.41)$ & 1.97 & 0.16 & $1.00(0.31-3.29)$ & 0.00 & 1.00 & 0.31 \\
\hline ARWMC & $1.02(0.92-1.14)$ & 0.16 & 0.69 & $0.95(0.82-1.10)$ & 0.52 & 0.47 & $1.10(0.93-1.32)$ & 1.22 & 0.27 & 0.19 \\
\hline Periventricular WMH & $1.00(0.45-2.21)$ & 0.00 & 1.00 & $0.72(0.24-2.20)$ & 0.32 & 0.57 & $1.33(0.41-4.25)$ & 0.23 & 0.64 & 0.46 \\
\hline Fazekas & $1.08(0.53-2.20)$ & 0.05 & 0.83 & $0.70(0.27-1.80)$ & 0.55 & 0.46 & $1.81(0.54-6.09)$ & 0.92 & 0.34 & 0.23 \\
\hline
\end{tabular}

$1.08(0.53-2.20)$

0.05

$0.83 \quad 0.70(0.27-1.80)$

0.55

0.46

$1.81(0.54-6.09)$

0.92

0.23

Notes: Medication resistance as measured with ATHF, Depression symptoms as a number on MADRS scale, Psychotic symptoms according to DSM-IV-TR criteria. Response to ECT is defined as 50\% improvement or more in MADRS scores from baseline during a course of ECT. In all bivariate analyses degree of freedom was 1. GCA: global cortical atrophy, ARWMC: Age-Related White Matter Changes scale. 


\section{Early-and Late-Onset Depression in Late Life}

In EOD more MTA was associated with higher odds for response, whereas in LOD less MTA was associated with higher odds for response. Although the interaction term "EOD/LOD $\times$ MTA" was statistically significant, the associations in the separate subsets (EOD and LOD) were not statistically significant. In patients with severe LLD, age at onset probably does not identify clinical subtypes.

\section{Predicting Response to ECT}

We set out to identify predictors of response more specific in LOD to explain its superior response rate compared with EOD. In our total sample, psychotic symptoms and less medication resistance were associated with better response, but these factors were similar in EOD and LOD. This is in contrast with a recent meta-analysis that failed to identify psychotic features as a positive predictor for ECT response. ${ }^{40}$ This finding may depend on several factors. Most studies were carried out in younger patients, and the definition of psychotic features is not unequivocal. Moreover, psychotic depressed patients may receive ECT earlier in their course of illness and thereby have shorter episode and less medication resistance.

The presence of psychotic features based on clinical judgment was found to be a robust predictor of response to ECT in several previous studies. ${ }^{41-43}$ Previously, a study from our own group on LLD treated with ECT found that depression with psychotic symptoms was significantly associated with absence of cognitive decline long-term follow-up. ${ }^{44}$

In our sample the median duration of the current episode was 6 months, similar in EOD and LOD. In EOD a shorter duration of the index episode was associated with higher response rates. In the aforementioned meta-analysis, ${ }^{40}$ duration of current episode, together with relative absence of medication failure, was found to be a robust clinical predictor of response to ECT. In responders the current episode had a weighted mean duration of 6.6 months versus 14 months in nonresponders. ${ }^{40}$ As in our sample, it seems likely that older patients receive ECT earlier in their course, because they may not tolerate pharmacotherapy. This may explain why age was not found to be a predictor for response to ECT in this metaanalysis contrary to previous findings. ${ }^{16,17,45}$

Higher response rates to ECT were not associated with absence of somatic illnesses, presence of cardio- vascular disease, or structural brain characteristics. Recently, in LLD patients treated with pharmacotherapy, the association of cerebrovascular risk and poor treatment outcome in LLD was reconfirmed. ${ }^{46}$ Cerebrovascular burden may hamper the effect of antidepressants in LLD. In our sample, before ECT, patients had received a median of 2 antidepressant trails, establishing failure to respond to pharmacotherapy. However, our results indicate that ECT is very effective even in pharmacotherapy-resistant LLD with vascular burden.

We were not able to explain the higher response rates in LOD by clinical or structural brain characteristics. The number of nonresponders with LOD was probably too low $(n=8)$ to find statistically significant associations.

\section{Strengths and Limitations}

The strength of our study is that we were able to include a substantial number of older patients treated with ECT and collect a comprehensive set of clinical data on all patients, including brain imaging. In most aspects, the patients included from the two sites were similar.

The study was parallel but subordinate to patient care, and therefore because some patients needed ECT before inclusion could be completed, some data (MRI scans, clinical scales) were missing. Nevertheless, $70 \%-99 \%$ of clinical rating scales were completed, and $72 \%$ of patients had an MRI scan before their first ECT. Data on age at first depressive episode were collected dichotomously, limiting analyses with age at onset as a continuous variable. Another limitation is that many statistical tests were performed, resulting in an increased risk for Type I errors. In this study we chose to include structural brain characteristics using visual rating scales for well-known age-related changes.

We used the MMSE to assess global cognitive change after ECT. However, the MODECT also included an extensive neuropsychological battery that will enable us to study specific changes in future reports. A comprehensive qualitative evaluation of imaging data was beyond the scope of this study. For clinical interpretation, our relatively large sample of LLD inpatients is small compared with epidemiologic studies, and the homogenous nature of our study, which was limited 
to severe LLD, may mean that our findings cannot be generalized to other patient groups.

In conclusion, although response rates to ECT in our sample of patients with LLD was high, patients with LOD showed the highest response rates. This difference could not be explained by differences in clinical profile or structural brain characteristics. Our results provide also evidence for the notion that ECT is most effective in LLD with psychotic symptoms.
Furthermore, we conclude that ECT is very effective in vascular burdened patients.

The authors thank Anna Paauw and Lianneke Egberink for their aid in data collection and management. A. Dols and F. Bouckaert contributed equally and share first authorship. M. Vandenbulcke was supported by the Research Foundation-Flanders (Fonds Wetenschappelijk Onderzoek, Project G.0746.09).

\section{References}

1. Lyness JM: Depression and comorbidity: objects in the mirror are more complex than they appear. Am J Geriatr Psychiatry 2008; $16: 181-185$

2. Kessler RC, Birnbaum H, Bromet E, et al: Age differences in major depression: results from the National Comorbidity Survey Replication (NCS-R). Psychol Med 2009; 40:225-237

3. Naismith SL, Norrie LM, Mowszowski L, et al: The neurobiology of depression in later-life: clinical, neuropsychological, neuroimaging and pathophysiological features. Prog Neurobiol 2012; 98: 99-143

4. Harald B, Gordon P: Meta-review of depressive subtyping models. J Affect Disord 2012; 139:126-140

5. Sachs-Ericsson N, Corsentino E, Moxley J, et al: A longitudinal study of differences in late- and early-onset geriatric depression: depressive symptoms and psychosocial, cognitive, and neurological functioning. Aging Ment Health 2013; 17:1-11

6. Alexopoulos GS, Young RC, Meyers BS, et al: Late-onset depression. Psychiatr Clin North Am 1988; 11:101-115

7. Mackin RS, Nelson JC, Delucchi KL, et al: Association of age at depression onset with cognitive functioning in individuals with latelife depression and executive dysfunction. Am J Geriatr Psychiatry 2014; 22:1633-1641

8. Hickie I, Naismith S, Ward PB, et al: Reduced hippocampal volumes and memory loss in patients with early- and late-onset depression. Br J Psychiatry 2005; 186:197-202

9. Dillon C, Allegri RF, Serrano CM, et al: Late- versus early-onset geriatric depression in a memory research center. Neuropsychiatr Dis Treat 2009; 5:517-526

10. Alexopoulos GS, Meyers BS, Young RC, et al: "Vascular depression" hypothesis. Arch Gen Psychiatry 1997; 54:915-922

11. Valkanova V, Ebmeier KP: Vascular risk factors and depression in later life: a systematic review and meta-analysis. Biol Psychiatry 2013; 73:406-413

12. Sheline YI, Pieper CF, Barch DM, et al: Support for the vascular depression hypothesis in late-life depression: results of a 2-site, prospective, antidepressant treatment trial. Arch Gen Psychiatry 2010; 67:277-285

13. Aizenstein HJ, Khalaf A, Walker SE, et al: Magnetic resonance imaging predictors of treatment response in late-life depression. J Geriatr Psychiatry Neurol 2014; 27:24-32

14. Sachs-Ericsson N, Moxley JH, Corsentino E, et al: Melancholia in later life: late and early onset differences in presentation, course, and dementia risk. Int J Geriatr Psychiatry 2014; 29: 943-951

15. Alvarez P, Urretavizcaya M, Benlloch L, et al: Early- and late-onset depression in the older: no differences found within the melancholic subtype. Int J Geriatr Psychiatry 2011; 26: 615-621
16. Tew JD Jr, Mulsant BH, Haskett RF, et al: Acute efficacy of ECT in the treatment of major depression in the old-old. Am J Psychiatry $1999 ; 156: 1865-1870$

17. Rhebergen D, Huisman A, Bouckaert F, et al: Older age is associated with rapid remission of depression after electroconvulsive therapy: a latent class growth analysis. Am J Geriatr Psychiatry 2015; 23:274-282

18. Unutzer J, Park M: Older adults with severe, treatment-resistant depression. JAMA 2012; 308:909-918

19. Spaans HP, Sienaert P, Bouckaert F, et al: Speed of remission in elderly patients with depression: electroconvulsive therapy v. medication. Br J Psychiatry 2015; 206:67-71

20. Stek ML, van der Wurff FFB, Hoogendijk WJG, et al: Electroconvulsive therapy for the depressed elderly. Cochrane Database Syst Rev 2003; 2:CD003593. doi:10.1002/14651858.CD003593

21. Oudega ML, van Exel E, Wattjes MP, et al: White matter hyperintensities, medial temporal lobe atrophy, cortical atrophy, and response to electroconvulsive therapy in severely depressed elderly patients. J Clin Psychiatry 2011; 72:104-112

22. Oudega ML, van Exel E, Stek ML, et al: The structure of the geriatric depressed brain and response to electroconvulsive therapy. Psychiatry Res 2014; 222:1-9

23. American Psychiatric Association: Diagnostic and Statistical Manual of Mental Disorders. 4th ed., text revision. Washington DC: American Psychiatric Press, 2000

24. Sheehan DV, Lecrubier Y, Sheehan KH, et al: The Mini-International Neuropsychiatric Interview (M.I.N.I.): the development and validation of a structured diagnostic psychiatric interview for DSM-IV and ICD-10. J Clin Psychiatry 1998; 59(suppl 20):22-33, quiz 34-57

25. Prudic J, Haskett RF, Mulsant B, et al: Resistance to antidepressant medications and short-term clinical response to ECT. Am J Psychiatry 1996; 153:985-992

26. Bohn MJ, Babor TF, Kranzler HR: The Alcohol Use Disorders Identification Test (AUDIT): validation of a screening instrument for use in medical settings. J Stud Alcohol 1995; 56:423-432

27. Montgomery SA, Asberg M: A new depression scale designed to be sensitive to change. Br J Psychiatry 1979; 134:382-389

28. Folstein MF, Folstein SE, McHugh PR: "Mini-Mental State." A practical method for grading the cognitive state of patients for the clinician. J Psychiatr Res 1975; 12:189-198

29. Fazekas F, Chawluk JB, Alavi A, et al: MR signal abnormalities at $1.5 \mathrm{~T}$ in Alzheimer's dementia and normal aging. AJR Am J Roentgenol 1987; 149:351-356

30. Wahlund LO, Barkhof F, Fazekas F, et al: A new rating scale for agerelated white matter changes applicable to MRI and CT. Stroke 2001; 32:1318-1322

31. Scheltens P, Leys D, Barkhof F, et al: Atrophy of medial temporal lobes on MRI in "probable" Alzheimer's disease and normal ageing: 


\section{Early-and Late-Onset Depression in Late Life}

diagnostic value and neuropsychological correlates. J Neurol Neurosurg Psychiatry 1992; 55:967-972

32. Pasquier F, Leys D, Weerts JG, et al: Inter- and intraobserver reproducibility of cerebral atrophy assessment on MRI scans with hemispheric infarcts. Eur Neurol 1996; 36:268-272

33. Birkenhager TK, Burggraaf JP, van den Broek WW, eds: [Richtlijn elektroconvulsietherapie.] Dutch Guideline on Electroconvulsive Therapy. Utrecht, the Netherlands: Uitgeverij de Tijdstroom, 2010

34. van den Broek WW, Birkenhager TK, de Boer D, et al: Richtlijn elektroconvulsietherapie. Utrecht, the Netherlands: Tijdstroom, 2010

35. Hawley CJ, Gale TM, Sivakumaran T: Defining remission by cut off score on the MADRS: selecting the optimal value.J Affect Disord 2002; 72:177-184

36. Kellner CH, Knapp R, Husain MM, et al: Bifrontal, bitemporal and right unilateral electrode placement in ECT: randomised trial. $\mathrm{Br}$ J Psychiatry 2010; 196:226-234

37. Van der Wurff FB, Stek ML, Hoogendijk WL, et al: Electroconvulsive therapy for the depressed elderly. Cochrane Database Syst Rev 2003; (2):CD003593

38. Blazer D, Bachar JR, Hughes DC: Major depression with melancholia: a comparison of middle-aged and elderly adults.J Am Geriatr Soc 1987 ; 35:927-932

39. Brown RP, Sweeney J, Loutsch E, et al: Involutional melancholia revisited. Am J Psychiatry 1984; 141:24-28
40. Haq AU, Sitzmann AF, Goldman ML, et al: Response of depression to electroconvulsive therapy: a meta-analysis of clinical predictors. J Clin Psychiatry 2015; 76:1374-1384

41. Buchan H, Johnstone E, McPherson K, et al: Who benefits from electroconvulsive therapy? Combined results of the Leicester and Northwick Park trials. Br J Psychiatry 1992; 160:355-359

42. Hickie I, Mason C, Parker G, et al: Prediction of ECT response: validation of a refined sign-based (CORE) system for defining melancholia. Br J Psychiatry 1996; 169:68-74

43. Petrides G, Fink M, Husain MM, et al: ECT remission rates in psychotic versus nonpsychotic depressed patients: a report from CORE. J ECT 2001; 17:244-253

44. Oudega ML, Dols A, Adelerhof I, et al: Contribution of white matter hyperintensities, medial temporal lobe atrophy and cortical atrophy on outcome, seven to twelve years after ECT in severely depressed geriatric patients. J Affect Disord 2015; 185: $144-148$

45. O'Connor MK, Knapp R, Husain M, et al: The influence of age on the response of major depression to electroconvulsive therapy: a C.O.R.E. Report. Am J Geriatr Psychiatry 2001; 9: 382-390

46. Bingham KS, Whyte EM, Meyers BS, et al: Relationship between cerebrovascular risk, cognition, and treatment outcome in latelife psychotic depression. Am J Geriatr Psychiatry 2015; 23 : $1270-1275$ 